\title{
Relationship of Micrococcus sp. ATCC 407 to the Status of Micrococcus freudenreichii Guillebeau ${ }^{1}$
}

\author{
I. J. McDONALD \\ Division of Biology, National Research Council of Canada, \\ Ottawa, Ontario K1A OR6
}

\begin{abstract}
Micrococcus sp. ATCC 407 (Micrococcus freudenreichii ATCC 407), a metabolically active organism, uses maltose, maltotriose, and maltotetraose but not glucose or other carbohydrates as carbon sources. Organic acids (e.g., succinate, lactate, acetate) and amino acids (e.g., dicarboxylic, alanine, histidine, and lysine) are used more readily than maltose and maltodextrins. The organism uses ammonia as a nitrogen source provided that the medium contains thiamine, biotin, methionine, and a suitable carbon source (e.g., succinate). In a medium containing biotin, thiamine, and methionine, glutamine or glutamic acid served as single sources of carbon and nitrogen for growth. Some characteristics of $M$. freudenreichii ATCC 407 are presented for consideration by the Subcommittee on Taxonomy of Staphylococci and Micrococci of the International Committee on Systematic Bacteriology before any decisions are reached concerning the status of Micrococcus freudenreichii. However, on the basis of the available evidence, it is suggested that ATCC 407 should not be designated as the neotype strain of the species and that the name Micrococcus freudenreichii should be placed on the list of nomina rejicienda as a nomen dubium.
\end{abstract}

In a recent paper, Bergan, $\mathrm{B} \phi \mathrm{v} r e$, and Hovig (5) discussed the status of the species Micrococcus freudenreichii Guillebeau. The authors examined the cultural and biochemical characteristics of several cultures labeled $M$. freudenreichii $(5,6)$, but they were unable to find any micrococcus which complied fully with the original description of the species (5). It was recommended that the Subcommittee on Taxonomy of Staphylococci and Micrococci evaluate the proposals: (i) that strain CCM 764 (a sub-culture of our $M$. freudenreichii ATCC 407 which we sent to the Czechoslovak Collection of Microorganisms in 1958) should be designated as a neotype strain of $M$. freudenreichii and that this species be defined accordingly or (ii) that the name $M$. freudenreichii should be placed in the list of nomina rejicienda as a nomen dubium.

During the course of investigations on proteinase production by Micrococcus sp. ATCC 407 (i.e., M. freudenreichii ATCC 407), we accumulated considerable data, published and unpublished, on the physiology of the organism. Because many items of these data are

1 NRCC no. 12217. relevant to the status of $M$. freudenreichii, they have been brought together for presentation herein.

\section{MATERIALS AND METHODS}

Bacterial strain. Micrococcus sp. ATCC 407 (M. freudenreichii ATCC 407) was obtained from N. Neilson, The University of British Columbia, Canada, and was maintained by monthly transfer on slants of blood-agar base (Difco). Stock cultures, maintained as cell suspensions in $15 \%$ glycerol, were frozen and stored at $-40 \mathrm{C}$.

Methods. The organism was characterized with procedures in the Manual of Microbiological Methods (24) as described previously (15). The oxidase test was that of Kovacs (13); production of phosphatase was detected with phenolphthalein phosphate in tryptone yeast extract (TYE) agar as described by Baird-Parker (2). For all of these tests, the organism was cultivated at 23 to $25 \mathrm{C}$.

Two broth media were used for determination of utilization of carbohydrates, organic and amino acids. The first was TYE broth, containing $0.1 \%$ each of tryptone and yeast extract. The second, synthetic broth (SM), contained: $\mathrm{NaCl}, 0.5 \mathrm{~g} ; \mathrm{KH}_{2} \mathrm{PO}_{4}, 0.2 \mathrm{~g}$; $\mathrm{NH}_{4} \mathrm{Cl}, 0.1 \mathrm{~g} ; \mathrm{NaHCO}_{3}, 0.1 \mathrm{~g} ; \mathrm{MgSO}_{4} \cdot 7 \mathrm{H}_{2} \mathrm{O}, 0.1 \mathrm{mg}$; $\mathrm{FeSO}_{4} \cdot 7 \mathrm{H}_{2} \mathrm{O}, \quad 0.1 \mathrm{mg}$; thiamine hydrochloride, $200 \mu \mathrm{g}$; biotin, $0.4 \mu \mathrm{g}$; DL-methionine, $1.0 \mathrm{mg}$; a carbon source, $0.5 \mathrm{~g}$ (usually); and distilled water, in a 
$100-\mathrm{ml}$ final volume of medium at $p \mathrm{H} \mathrm{7.0.} \mathrm{Media} \mathrm{were}$ sterilized at $121 \mathrm{C}$ for $15 \mathrm{~min}$. Maltose $(20 \%)$ was generally sterilized separately at $121 \mathrm{C}$ for $15 \mathrm{~min}$ and added to cool sterile basal medium. Maltose polymers (i.e., maltotriose, etc.), L-glutamine, $\alpha$-ketoglutarate, oxaloacetate, and pyruvate were added as solutions sterilized by filtration.

All experimental cultures were grown in 250-ml Erlenmeyer flasks, containing 50 to $100 \mathrm{ml}$ of medium, on a platform shaker operating at 100 $\mathrm{rev} / \mathrm{min}$. Inocula $(0.2$ to $0.5 \%)$ were of cells, washed two or three times in water, from TYE or SM.

For determinations of ammonia and carbon dioxide production from organic and amino acids, cells grown in TYE-maltose or SM-glutamic acid-maltose for 40 to $48 \mathrm{hr}$ were collected, washed aseptically, and suspended in sterile salt buffer $\left(\mathrm{NaCl}, 0.5 \%, \mathrm{KH}_{2} \mathrm{PO}_{4}\right.$, $0.2 \%$, at $p \mathrm{H} 7.0$ ) to about five times their original concentration. Cells were mixed with sterile substrate in one arm of a Rogers-Eldrige tube; the other arm contained standardized $1.0 \mathrm{~N} \mathrm{KOH}$. The stoppered tubes were shaken at $25 \mathrm{C}$ for 18 to $70 \mathrm{hr}$. Carbon dioxide liberated from the substrate was determined by titration of the alkali to the phenolphthalein end point after the addition of excess barium chloride (20). Ammonia was detected in the reaction supernatant fluid by Nessler's reagent.

The amount of carbohydrate in culture media was determined by the anthrone method (22) or by the Nelson-Somogyi method (20). Maltotriose, maltotetraose, maltopentaose, and maltohexaose were isolated from technical maltose on Dowex-50-X2 in the lithium form as described previously (18).

\section{RESULTS}

Most of the results were obtained with $M$. freudenreichii ATCC 407 originally received from N. Neilson. Over a period of several years, cultures from ATCC and from Cornell University (H. B. Naylor) were compared with our stock culture primarily for characteristics associated with proteinase activity. In these respects, all three cultures behaved identically.

Classification. Micrococcus sp. ATCC 407 had characteristics, as reported previously (15), indicating that it belonged to the family Micrococcaceae [i.e., a gram-positive, aerobic, nonspore-forming, nonmotile, catalase-positive coccus occurring in tetrads and irregular clusters (7)]. However, it was not possible to identify the species to which the organism belonged because of its further characteristics: inability to reduce nitrates; inability to grow with ammonium phosphate as the sole source of nitrogen [Hucker's medium (7)] ; inability to hydrolyze urea; inability to produce acid from carbohydrates; inability to clot milk; and proteolytic activity (15). More recently, it was found that ATCC 407 is phosphatase- and oxidase-negative. [Note, however, Auletta and Kennedy (1) reported that two cultures labeled ATCC 407 , one of which they received from the author, were oxidase-positive!] During the course of studies on proteinase production by ATCC 407 , the following information, of value in the classification of the organism, has accumulated.

Effect of aeration. It was reported previously (16) that Micrococcus sp. ATCC 407 grew poorly under an atmosphere of nitrogen. It has since been found that, under stringent anaerobic conditions, no growth occurs. For example, in cultures grown in TYE with shaking at $25 \mathrm{C}$ for $41 \mathrm{hr}$ under air, the optical density increased from 0.03 to 0.74 ; under nitrogen the optical density remained at 0.03 . Therefore, the organism is an obligate aerobe, and cognizance of this fact must be taken when studies on growth are performed, as noted previously (9). Unless stated otherwise, results in this paper-were obtained with aerated cultures or cell suspensions.

Carbohydrate utilization. The cultivation of the organism in TYE broth containing carbohydrates and bromocresol purple indicator resulted in alkaline reactions with all carbohydrates tested. This was true whether growth was in static test tubes or in aerated (by shaking) Erlenmeyer flasks. It was found, however, that maltose, but not glucose, disappeared from the medium during aerobic growth of ATCC 407 (16). Also, maltose was the only one of 15 common carbohydrates that stimulated growth and disappeared from the medium during growth of ATCC 407 in TYE (Table 1). In other experiments, neither glycerol nor mannitol disappeared from the medium (data not shown). Similar results were obtained when SM containing glutamic acid, glutamine, or lysine was the basal medium; maltose was the only carbohydrate to stimulate growth and disappear from the medium. In all of these cultures, the final $p \mathrm{H}$ was alkaline to bromocresol purple (in TYE, $p \mathrm{H} 8.0$ to 8.6 ; in SM, $p \mathrm{H} 7.0$ to 8.4 ).

Maltose (G-2), therefore, appeared to be the only carbohydrate used for growth by ATCC 407. However, when the maltodex trins, maltotriose (G-3) and maltotetraose (G-4), were tested, they also were used (18). With cell suspensions, maltodextrins but not glucose disappeared from reaction mix tures (26). Only the sugar added was detected on chromatograms of the reaction mixtures, except with maltohexaose where some external maltose appeared during the incubation (Table 2). The 
TABLE 1. Utilization of carbohydrates by Micrococcus sp. ATCC $407^{a}$

\begin{tabular}{|c|c|c|c|c|c|}
\hline \multirow{2}{*}{$\begin{array}{l}\text { Addition } \\
\text { to basal } \\
\text { medium }^{b}\end{array}$} & \multirow{2}{*}{$\begin{array}{c}\text { Growth } \\
\text { (OD at } 660 \mathrm{~nm} \\
\text { at } 48 \mathrm{hr} \text { ) }\end{array}$} & \multirow{2}{*}{$\begin{array}{l}p \mathrm{H} \text { at } \\
48 \mathrm{hr}\end{array}$} & \multicolumn{3}{|c|}{$\begin{array}{c}\text { Carbohydrate } \\
(\text { OD at } 540 \mathrm{~nm}) \times 10^{2} d\end{array}$} \\
\hline & & & $0 \mathrm{hr}$ & $48 \mathrm{hr}$ & $\triangle \mathrm{OD}$ \\
\hline None $\ldots \ldots \ldots$ & 0.89 & 8.6 & & & \\
\hline Arabinose $\ldots .$. & 0.88 & 8.6 & 22 & 23 & +1 \\
\hline Ribose $\ldots \ldots \ldots$ & 0.89 & 8.6 & 22 & 23 & +1 \\
\hline Xylose ....... & 0.89 & 8.6 & 26 & 27 & +1 \\
\hline Rhamnose .... & 0.89 & 8.5 & 76 & 76 & 0 \\
\hline Fructose . . . . . & 0.88 & 8.6 & 88 & 85 & -3 \\
\hline Galactose ..... & 0.87 & 8.6 & 54 & 55 & +1 \\
\hline Glucose $\ldots \ldots$ & 0.87 & 8.5 & 78 & 79 & +1 \\
\hline Mannose ...... & 0.89 & 8.6 & 50 & 50 & 0 \\
\hline Maltose $\ldots .$. & 1.20 & 8.0 & 100 & 22 & -78 \\
\hline Melibiose ..... & 0.90 & 8.5 & 66 & 67 & +1 \\
\hline Lactose $\ldots \ldots$ & 0.88 & 8.6 & 68 & 66 & -2 \\
\hline Sucrose $\ldots . .$. & 0.87 & 8.6 & 89 & 88 & -1 \\
\hline Trehalose ..... & 0.90 & 8.5 & 76 & 75 & -1 \\
\hline Raffinose ..... & 0.89 & 8.5 & 73 & 72 & -1 \\
\hline Salicin ...... & 0.86 & 8.5 & 57 & 57 & 0 \\
\hline
\end{tabular}

${ }^{a}$ Received as Micrococcus freudenreichii.

$b$ Basal medium, TYE plus $0.5 \%$ carbohydrate.

$c$ Cultures incubated $48 \mathrm{hr}$ at $25 \mathrm{C}$ with shaking. $\mathrm{OD}$, optical density.

$d$ Supernatant fluids from cultures at 0 time and after incubation for $48 \mathrm{hr}$ were diluted $1: 10 ; 3.0 \mathrm{ml}$ of diluted supernatant, $1.0 \mathrm{ml}$ of water, and $8.0 \mathrm{ml}$ of anthrone were mixed (20). $\triangle O D$ indicates the degree of carbohydrate utilization.

organism seemed to take up the di- and trisaccharides directly without prior hydrolysis (26), and it is possible that the tetra- and pentasaccharides behaved similarly. On the basis of the evidence available, it was suggested that the uptake mechanism was specific for sugars having an $\alpha-1,4$ linkage (26).

With respect to the ability of the organism

TABLE 2. Disappearance of maltose and maltodextrins from reaction mixtures with cells of Micrococcus sp. ATCC $407^{a}$

\begin{tabular}{|c|c|c|c|c|c|}
\hline \multirow[b]{2}{*}{ Carbohydrate $^{b}$} & \multicolumn{4}{|c|}{$\begin{array}{c}\text { Sugar as maltose }(\mu \mathrm{g} / \mathrm{ml}) \\
\text { after } c\end{array}$} & \multirow{2}{*}{$\begin{array}{l}\text { Chromatogram } \\
\text { at } 60 \mathrm{~min}\end{array}$} \\
\hline & $0 \mathrm{~min}$ & $15 \mathrm{~min}$ & $30 \mathrm{~min}$ & $60 \mathrm{~min}$ & \\
\hline Glucose (G-1) & 544 & & & 560 & G-1 \\
\hline Maltose (G-2) . . . & 762 & 532 & 120 & 56 & G-2 \\
\hline Maltotriose (G-3) .. & 720 & 114 & 40 & 40 & G-3 \\
\hline Maltotetraose $(G-4)$ & 540 & 94 & 70 & 64 & $\mathrm{G}-4$ \\
\hline Maltopentaose (G-5) & 440 & 136 & 78 & 80 & G-5 \\
\hline Maltohexaose (G-6) & 596 & 492 & 420 & 240 & $\mathrm{G}-2$ and $\mathrm{G}-6$ \\
\hline
\end{tabular}

${ }^{a}$ Received as Micrococcus freudenreichii.

${ }^{b}$ Reaction mixture: $0.5 \% \mathrm{NaCl}, 0.2 \% \mathrm{KH}_{2} \mathrm{PO}_{4}(p \mathrm{H} 7.0)$, carbohydrate, and cell suspension. Incubation at $25 \mathrm{C}$ on platform shaker $(100 \mathrm{rev} / \mathrm{min})$.

${ }^{c}$ Carbohydrate in cell-free reaction mixture was determined by the Nelson-Somogyi method (19). 
to use G-2, G-3, and G-4 without prior hydrolysis, an interesting observation was made with lysozyme lysates of cells of ATCC 407. When such extracts were mixed with carbohydrates and incubated, the following sugars were hydrolyzed to yield free glucose as detected by paper chromatography: starch, maltose, maltotriose, maltotetraose, sucrose, and turanose. Sugars that were not hydrolyzed to yield glucose were: cellobiose, trehalose, lactose, melibiose, melezitose, glycogen, and raffinose.

ATCC 407 grew poorly in synthetic medium with either maltose, maltotriose, or maltotetraose as the sole source of carbon (18). The G-3 and G-4 sugars resulted in more rapid growth than the G-2, but none of the three sugars supported rapid growth (18). When stimulation of growth and suppression of proteinase production by ATCC 407 was determined in SM containing glutamine, the order of effectiveness of the three homologues was G-4 > G-3 > G-2. The rate at which carbohydrate disappeared from the medium was in this same order (18). These results suggest that ATCC 407 utilizes G-3 and G-4 more readily than G-2. The uptake of sugars by cell suspensions confirms this view (26; Table 2).

Thus, from the point of view of classification of Micrococcus sp. ATCC 407, the following facts are significant. (i) The organism utilizes maltose and maltodextrins but not glucose or any other common carbohydrate; (ii) acid production from sugars cannot be detected qualitatively; and (iii) neither lactose nor its component monosaccharides, glucose and galactose, are used by the organism.
Action on litmus milk. When Micrococcus sp. ATCC 407 was grown in litmus milk in test tubes, prolonged incubation resulted in an alkaline reaction and in marked digestion of the casein. No evidence of acid production (cf. Table 1, lactose not used) or of ropiness was observed. When the growth conditions were optimal (i.e., shaken Erlenmeyer flasks) alkali production and casein digestion occurred in 2 to 3 days.

Ammonia utilization. The ability of micrococci to use ammonia as a source of nitrogen is usually determined by the ability of the organism to grow on ammonium phosphateglucose agar (7). A positive reaction means not only that ammonia serves as the nitrogen source but also that glucose serves as a carbon source. In studies on the nutritional requirements, it was shown that ATCC 407 had absolute requirements for thiamine and methionine (15, 17). Clearly then, ammonia cannot serve as a sole source of nitrogen for this organism. It has been suggested $(10,23)$ that carry-over of trace nutrients with the inoculum may allow nutritionally demanding organisms such as ATCC 407 to grow with ammonia. However, since ATCC 407 does not use glucose as a carbon source (see Table 1), even carry-over of trace nutrients would not allow growth on Hucker's medium.

On the basis of the lack of growth on Hucker's medium, one would conclude that ATCC 407 does not use ammonia as a source of nitrogen. However, it is evident from previous studies (18) and from results shown in Tables 3 and 4 that, in a synthetic medium containing thiamine, biotin, methionine, and a utilizable carbon source, ammonia can serve as a source of nitrogen for growth.

TABLE 3. Effect of ammonia on growth of Micrococcus sp. $A T C C 407^{a}$ in synthetic medium

\begin{tabular}{|c|c|c|c|}
\hline \multirow[b]{2}{*}{ Addition to basal medium $b$} & \multicolumn{3}{|c|}{ Optical density at $660 \mathrm{~nm}$} \\
\hline & $40 \mathrm{hr}$ & $48 \mathrm{hr}$ & $72 \mathrm{hr}$ \\
\hline Succinate $(0.5 \%)$. & 0.02 & 0.03 & 0.04 \\
\hline Succinate $+\mathrm{NH}_{4} \mathrm{Cl}(0.1 \%)$ & 0.58 & 0.65 & 0.66 \\
\hline Glutamic acid $(0.5 \%) \ldots$ & 0.21 & 0.40 & 0.65 \\
\hline Glutamic acid $+\mathrm{NH}_{4} \mathrm{Cl} \ldots \ldots$ & 0.02 & 0.09 & 0.30 \\
\hline Glutamine $(0.5 \%) \ldots \ldots$ & 0.15 & 0.24 & 0.37 \\
\hline Glutamine $+\mathrm{NH}_{4} \mathrm{Cl}$ & 0.11 & 0.17 & 0.28 \\
\hline
\end{tabular}

$a^{a}$ Received as Micrococcus freudenreichii.

${ }^{b}$ Basal medium SM without $\mathrm{NH}_{4} \mathrm{Cl}, \mathrm{NaHCO}_{3}$, and maltose. 
TABLE 4. Growth of Micrococcus sp. ATCC $407^{a}$ in synthetic medium with various carbon sources

\begin{tabular}{|c|c|c|c|c|c|}
\hline \multirow[b]{2}{*}{$\begin{array}{c}\text { Substrate } \\
(0.5 \%)\end{array}$} & \multicolumn{2}{|c|}{ Growth } & \multirow[b]{2}{*}{$\begin{array}{c}\text { Substrate } \\
(0.5 \%)\end{array}$} & \multicolumn{2}{|c|}{ Growth } \\
\hline & Basal $^{b}$ & $\underset{\text { maltose }}{\text { Basal }+}$ & & Basal $^{b}$ & $\begin{array}{c}\text { Basal }+ \\
\text { maltose }^{b}\end{array}$ \\
\hline None . . . . . . . . . & 0 & $+($ very slow $)$ & L-Phenylalanine $\ldots$. & 0 & + \\
\hline L-Asparagine $\ldots \ldots$. & + & + & L-Proline $\ldots \ldots \ldots$ & 0 & + \\
\hline DL-Aspartic acid . . . & + & + & Glycine $\ldots \ldots \ldots$ & 0 & $+($ very slow $)$ \\
\hline L-Glutamine $\ldots \ldots$ & + & + & DL-Ornithine $\ldots \ldots$ & 0 & $+($ very slow $)$ \\
\hline L-Glutamic acid $\ldots$ & + & + & DL-Valine $\ldots .$. & 0 & $+($ very slow $)$ \\
\hline L-Histidine $\ldots \ldots \ldots$ & + & + & DL-Isoleucine . . & 0 & 0 \\
\hline L-Lysine $\ldots \ldots \ldots$ & + & + & DL-Serine $\ldots \ldots$ & 0 & 0 \\
\hline DL-Alanine $\ldots \ldots \ldots$ & $+($ slow $)$ & + & DL-Threonine . . & 0 & 0 \\
\hline L-Arginine $\ldots \ldots \ldots$ & 0 & + & DL-Tryptophan . ... & 0 & 0 \\
\hline L-Leucine $\ldots \ldots \ldots$ & 0 & + & & & \\
\hline Acetate ........ & + & + & Malate ......... & NT & + \\
\hline Citrate .......... & 0 & 0 & Oxaloacetate ...... & NT & + \\
\hline Fumarate $\ldots \ldots \ldots$ & NT & + & Pyruvate ........ & + & + \\
\hline$\alpha$-Ketoglutarate . . . & NT & + & Succinate $\ldots \ldots \ldots$ & + & + \\
\hline Lactate ......... & + & + & & & \\
\hline
\end{tabular}

\footnotetext{
${ }^{a}$ Received as Micrococcus freudenreichii.

${ }^{b}$ Basal medium SM with and without maltose $(0.4 \%)$. Incubation at $25 \mathrm{C}$ with shaking. Symbols: + , growth; 0 , no growth; NT, not tested.
}

Organic and amino acid utilization. In SM medium containing thiamine, biotin, methionine, and ammonia, ATCC 407 utilized any one of a number of organic and amino acids as carbon sources (Tables 3 and 4), and, as shown previously, maximum growth (optical density) was achieved more readily with these compounds as carbon sources than with maltose, maltotriose, etc. (18). It was shown also that maltose stimulated growth in amino acid media (18). Other amino acids supported growth in the presence but not in the absence of maltose (Table 4). Thus, carbon requirements for growth of the organism could be met by any one of several organic or amino acids but only poorly by maltose. The results suggest, however, that maltose exerts a sparing action on carbon requirements. In SM medium containing maltose but not ammonia or bicarbonate, ATCC 407 grew with glutamic acid, glutamine, aspartic acid, or asparagine (17), thus indicating that these amino acids were used as nitrogen sources for growth. In this medium, methionine $(0.5 \%)$ alone did not support growth. In SM medium without maltose, ammonia, or bicarbonate, either glutamine or glutamic acid supported growth (Table 3), indicating that these two served as single sources of carbon and nitrogen, provided traces of thiamine, biotin, and methionine were present.

When suspensions of ATCC 407 cells were incubated with various substrates, carbon dioxide was released from organic acids, whereas carbon dioxide and ammonia were released from amino acids (Table 5). Thus, under aerobic conditions, ATCC 407 produces carbon dioxide from organic and amino acids. Some of this carbon dioxide probably is in turn metabolized, because it has been shown that carbon dioxide fixation, catalyzed by malic enzyme, occurs in ATCC 407 (14). Also under aerobic conditions, ATCC 407 releases ammonia from several amino acids, and some of this may also be utilized by the organism.

\section{DISCUSSION}

The above results reveal some facets of the physiology of Micrococcus sp. ATCC 407 that require consideration in the classification of the organism (Table 6). As has been stated previously (9), aerobic micrococci should be studied by using methods adapted to their physiology. First, it is clear that ATCC 407 is an obligate aerobe, and so, to be meaningful, tests must be done aerobically. Second, the organism uses ammonia as a source of nitrogen when a 
TABLE 5. Production of ammonia and carbon dioxide from various substrates by washed cells of Micrococcus sp. ATCC $407^{a}$

\begin{tabular}{|c|c|c|c|c|}
\hline \multicolumn{3}{|c|}{$\begin{array}{l}\text { Cells from glutamate-maltose } \\
\text { broth }^{b}\end{array}$} & \multicolumn{2}{|l|}{ Cells from TYE broth ${ }^{b}$} \\
\hline Substrate & $\mathrm{CO}_{2}$ & $\mathrm{NH}_{3}$ & Substrate & $\mathrm{NH}_{3}$ \\
\hline DL-Alanine $\ldots \ldots \ldots \ldots$ & + & + & L-Arginine $\ldots$ & + \\
\hline L-Glutamic acid $\ldots \ldots$. & + & + & DL-Ornithine $\ldots \ldots \ldots$ & + \\
\hline L-Leucine $\ldots \ldots \ldots$ & + & + & DL-Phenylalanine $\ldots \ldots$ & + \\
\hline L-Lysine $\ldots \ldots \ldots \ldots$ & + & + & L-Tyrosine $\ldots \ldots$ & 0 \\
\hline L-Proline $\ldots \ldots \ldots \ldots$ & + & + & & \\
\hline Maltose ............. & + & 0 & & \\
\hline Lactate ............ & + & 0 & & \\
\hline Succinate $\ldots \ldots \ldots$ & + & 0 & & \\
\hline
\end{tabular}

${ }^{a}$ Received as Micrococcus freudenreichii.

${ }^{b}$ Aseptically collected cells were incubated with substrate in RogersEldrige tubes; $\mathrm{CO}_{2}$ was trapped in $\mathrm{N}-\mathrm{KOH}$ and titrated (20); $\mathrm{NH}_{3}$ was detected with Nessler's reagent.

suitable carbon source is supplied. Third, the organism clearly has an unusual ability to use maltodextrins as carbon sources, and, finally, the organism uses a wide variety of organic and amino acids as carbon sources.

Failure to recognize the aerobic nature of ATCC 407 can lead to erroneous results from biochemical and physiological tests dependent upon growth. For example, Bergan et al. (6) reported that ATCC 407 failed to split arginine, lysine, or ornithine when tested by the method of Mфller (19). Since the method depends on anaerobic growth, it is not surprising that their results were negative. The present results show that, under aerobic conditions, ATCC 407 splits these three amino acids and several others to yield carbon dioxide and ammonia.

Micrococcus sp. ATCC 407 was called Staphylococcus afermentans by Shaw, Stitt, and Cowan (23) and was placed in Micrococcus subgroup 7 by Baird-Parker (2) mainly because it failed to form acid from glucose and other carbohydrates. It is now apparent that ATCC 407 has specific mechanisms for the utilization of maltose and maltodextrins, which are $\alpha-1,4$ linked sugars (Table 2 and reference 26). This fact should be of considerable value in classifying the organism. It is not known whether the ability to use maltodextrins is related to the usual habitat of the organism, but it would be of interest to attempt to isolate similar organisms from malt worts, etc.

Schemes designed to identify and classify members of the genus Micrococcus do not include determination of the ability of organisms to use amino acids and organic acids for growth. However, the ability of ATCC 407 and other micrococci $(9,27)$ to grow with a wide variety of carbon sources suggests that tests for utilization of organic and amino acids might be useful for separating species of micrococci.

In recent classification schemes, the weakly glucose-oxidizing micrococci have been placed in a single species $(12,23)$, and Baird-Parker considers Micrococcus luteus the appropriate name for this species (3). According to this view, the organisms $M$. flavus, $M$. lysodeikticus, M. citreus, $M$. sodonensis, Sarcina lutea, Staphylococcus afermentans, etc. are members of the same species. (The list presumably includes ATCC 407 as $S$. afermentans.) Several of these organisms (M. flavus, $M$. citreus, $S$. lutea) have cell walls with the same peptidoglycan structure as those of M. lysodeikticus (8), and this is taken as evidence in support of their grouping as M. luteus (4). However, more recently, cell walls of $M$. freudenreichii ATCC 407 and $M$. luteus ATCC 385 were shown to have high concentrations of glucosamine, glucomuramic acid, alanine, and glutamic acid (25). The walls of these two organisms differed from those of $M$. lysodeikticus, $M$. citreus, and another strain of M. luteus (ATCC 398). It is this latter strain that has been suggested as the neotype strain by Kocur and Martinec (12) and by Auletta and Kennedy (1). The DNA base 
TABLE 6. Some characteristics of Micrococcus sp. ATCC 407

\begin{tabular}{|c|c|c|}
\hline Character & Reaction & Comments \\
\hline Anaerobic growth & 0 & ATCC 407 is an obligate aerobe \\
\hline \multicolumn{3}{|l|}{ Ammonia as nitrogen source } \\
\hline Hucker's medium (7) & 0 & $\begin{array}{l}\text { Methionine and thiamine required; glucose } \\
\text { not utilized }\end{array}$ \\
\hline $\begin{array}{l}\text { Medium with growth factors } \\
\text { and suitable carbon source }\end{array}$ & + & $\begin{array}{l}\text { Succinate (lactate, ace tate, etc.) as } \\
\text { carbon source }\end{array}$ \\
\hline \multicolumn{3}{|l|}{ Carbohydrate utilization } \\
\hline Acid formation, qualitative & 0 & $\begin{array}{l}\text { Ammonia from peptone masks possible acid } \\
\text { reaction }\end{array}$ \\
\hline $\begin{array}{l}\text { Quantitative disappearance maltose } \\
\text { (maltotriose, maltotetraose) }\end{array}$ & + & \\
\hline $\begin{array}{l}\text { Glucose, other hexoses and disaccharides, } \\
\text { pentoses, mannitol and glycerol }\end{array}$ & 0 & \\
\hline Litmus milk & $\mathrm{Alk}^{a}$ & No acid; casein digested; no ropiness \\
\hline \multicolumn{3}{|l|}{ Carbon sources (Table 2) } \\
\hline Succinate, lactate, pyruvate, ace tate & + & \\
\hline Citrate & 0 & \\
\hline $\begin{array}{l}\text { L-Aspartate, DL-asparagine, } \\
\text { L-glutamate, L-glutamine }\end{array}$ & + & \\
\hline L-Histidine, L-lysine & + & \\
\hline L-Alanine & + & (Growth slow) \\
\hline \multicolumn{3}{|l|}{ Ammonia from (Table 4) } \\
\hline Arginine, ornithine, lysine & + & Several others positive \\
\hline \multicolumn{3}{|l|}{ Enzymes } \\
\hline Catalase & + & \\
\hline Urease, oxidase, and phosphatase & 0 & \\
\hline
\end{tabular}

$a_{\text {Alkaline. }}$

composition of $M$. freudenreichii ATCC 407 is 58 to $59 \%$ guanine plus cytosine $(1,6)$ compared to $66 \%$ for $M$. luteus ATCC 398 (1) and to 35 and $69 \%$ for $S$. afermentans NCTC 4819 and 7495 , respectively (1). These observations, 'therefore, suggest that the weakly glucose-oxidizing micrococci should not be lumped together as $M$. luteus because they are indeed "a miscellaneous collection of morphological and physiological types" as observed previously by Baird-Parker (2). The observations suggest specifically that $M$. freudenreichii ATCC 407 should not be considered as a strain of $M$. luteus.

The questions posed by Bergan et al. (5) were whether $M$. freudenreichii CCM 764 (= ATCC 407) should be designated the neotype strain of the species and whether the name
M. freudenreichii should be rejected. From the data presented herein, it is clear that ATCC 407 is a unique organism having considerably more metabolic activity than one might suspect from the usual description of $M$. freudenreichii (7) or from results obtained by other investigators (6, 23 ). It is clear also that, should $M$. freudenreichii CCM 764 be designated the neotype strain, any description of the species will have to be modified extensively to include characteristics (Table 6) not given in the current description $(5,7)$. Thus the ability to use maltose, maltotriose, maltotetraose, and maltopentaose without prior hydrolysis and the inability to use glucose would be important characteristics in the description of the organism.

It should be noted that Evans et al. (10) 
suggested that new species should not be established on the basis of a study of one or two strains no matter how unique their characteristics might be. Because all cultures of $M$. freudenreichii fitting the description of ATCC 407 (= CCM 764) apparently are subcultures of one original isolate (5), a similar criterion probably should apply. Although Hucker (11) states that $M$. freudenreichii is one of the most common white micrococci occurring in milk, Bergan et al. (5), in an examination of micrococci from world sources, were unable to find any which complied fully with the few characteristics given in the description of the species (7). This result confirms our limited observations (unpublished data) on micrococci isolated from Canadian Cheddar cheese and strongly suggests that the species is inadequately described.

The above data and comments are presented for consideration by the Subcommittee on Taxonomy of Staphylococci and Micrococci of the International Committee on Systematic Bacteriology before any decisions are reached concerning the status of $M$. freudenreichii. In the author's view, the evidence suggests that it would be undesirable to designate ATCC 407 as the neotype strain of $M$. freudenreichii and that it would be desirable to have the name Micrococcus freudenreichii placed on the list of nomina rejicienda as a nomen dubium.

\section{ACKNOWLEDGMENT}

The technical assistance of Alice K. Chambers and Dorothy Stotesbury is gratefully acknowledged.

\section{LITERATURE CITED}

1. Auletta, A. E., and E. R. Kennedy. 1966. Deoxyribonucleic acid base composition of some members of the Micrococcaceae. J. Bacteriol. 92:28-34.

2. Baird-Parker, A. C. 1963. A classification of micrococci and staphylococci based on physiological and biochemical tests. J. Gen. Microbiol. 30:409-427.

3. Baird-Parker, A. C. 1965 . The classification of staphylococci and micrococci from world-wide sources. J. Gen. Microbiol. 38:363-387.

4. Baird-Parker, A. C. 1970 . The relationship of cell wall composition to the current classification of staphylococci and micrococci. Int. J. Syst. Bacteriol. 20:483-490.

5. Bergan, T., K. Bøvre, and B. Hovig. 1970. Present status of the species Micrococcus freudenreichii Guillebeau 1891. Int. J. Syst. Bacteriol. 20:249-254.

6. Bergan, T., K. Børvre, and B. Hovig. 1970. Reisolation of Micrococcus mucilaginosus Migula 1900. Acta Pathol. Microbiol. Scand. Sect. B. 78:85-97.
7. Breed, R. S., E. G. D. Murray, and N. R. Smith. 1957. Bergey's manual of determinative bacteriology, 7th ed. The Williams \& Wilkins Co., Baltimore.

8. Campbell, J. N., M. Leyh-Bouille, and J. M. Ghuysen. 1969. Characterization of the Micrococcus lysodeikticus type of peptidoglycan in walls of other Micrococcaceae. Biochemistry 8:193-200.

9. Eisenberg, R. C., and J. B. Evans. 1963. Energy and nitrogen requirements of Micrococcus roseus. Can. J. Microbiol. 9:633-642.

10. Evans, J. B., W. L. Bradford Jr., and C. F. Niven Jr. 1955. Comments concerning the taxonomy of the genera Micrococcus and Staphylococcus. Int. Bull. Bacteriol. Nomencl. Taxon. 5:61-66.

11. Hucker, G. J. 1928. Studies on the coccaceae. IX. Further studies on the classification of the micrococci. New York State Agr. Expt. Sta. Tech. Bull. no. 135.

12. Kocur, M., and T. Martinec. 1962. A taxonomic study of the genus Micrococcus. Folia Fac. Sci. Nat. Univ. Purkynianae Brunensis Biol. 3:1-121.

13. Kovacs, N. 1956. Identification of Pseudomonas pyocyanea by the oxidase reaction. Nature (London) 178:703.

14. Matula, T., I. J. McDonald, and S. M. Martin. 1969. $\mathrm{CO}_{2}$ fixation by malic enzyme in a species of Micrococcus. Biochem. Biophys. Res. Commun. 34:795-802.

15. McDonald, I. J. 1960. A minimal synthetic medium supporting growth of a Micrococcus species. Can. J. Microbiol. 6:251-256.

16. McDonald, I. J. 1961. Proteinase production in relation to growth of a Micrococcus species. Can. J. Microbiol. 7:111-117.

17. McDonald, I. J. 1963. Methionine requirement for growth of a species of Micrococcus. Can. J. Microbiol. 9:415-416.

18. McDonald, I. J., and A. K. Chambers. 1966. Regulation of proteinase formation in a species of Micrococcus. Can. J. Microbiol. 12:1175-1185.

19. Møller, V. 1955. Simplified tests for some amino acid decarboxylases and for the arginine dihydrolase system. Acta Pathol. Microbiol. Scand. 36:158-172.

20. Neish, A. C. 1952. Analy tical methods for bacterial fermentations. Report no. 46-8-3 (2nd rev.), Prairie Regional Laboratory, National Research Council of Canada.

21. Perry, J. J., and J. B. Evans. 1960. Oxidative metabolism of lactate and acetate by Micrococcus sodonensis. J. Bacteriol. 79:113-118.

22. Scott, T. A., and E. H. Melvin. 1953. Determination of dextran with anthrone. Anal. Chem. 25:1656-1661.

23. Shaw, C., J. M. Stitt, and S. T. Cowan. 1951. Staphylococci and their classification. J. Gen. Microbiol. 5:1010-1023.

24. Society of American Bacteriologists Committee on Bacteriological Technic. 1957. Manual of 
microbiological methods. McGraw-Hill Book Co., Inc., New York.

25. Wheat, R. W., and J. M. Ghuysen. 1971. Occurrence of glucomuramic acid in gram-positive bacteria. J. Bacteriol. 105:1219-1221.

26. Williams, P. J. LeB., and I. J. McDonald. 1966.
Permeability of a micrococcal cell to maltose and some related sugars. Can. J. Microbiol. 12:1213-1223.

27. Wolin, H. L., and H. B. Naylor. 1957. Basic nutritional requirements of Micrococcus lysodeikticus. J. Bacteriol. 74:163-167. 